\title{
Application of preoperative ultrasound features combined with clinical factors in predicting HER2-positive subtype (non-luminal) breast cancer
}

Jin Zhou ${ }^{1,3+}$, An-qi Jin ${ }^{3 \dagger}$, Shi-chong Zhou ${ }^{1,3^{*}}$, Jia-wei Li ${ }^{1,3}$, Wen-xiang Zhi ${ }^{1,3}$, Yun-xia Huang ${ }^{1,3}$, Qian Zhu ${ }^{1,3}$, Lang Qian ${ }^{1,3}$, Jiong Wu $\mathbf{u}^{2,3}$ and Cai Chang ${ }^{1,3^{*}}$

\begin{abstract}
Background: Human epidermal growth factor receptor2+ subtype breast cancer has a high degree of malignancy and a poor prognosis. The aim of this study is to develop a prediction model for the human epidermal growth factor receptor2+ subtype (non-luminal) of breast cancer based on the clinical and ultrasound features related with estrogen receptor, progesterone receptor, and human epidermal growth factor receptor2.

Methods: We collected clinical data and reviewed preoperative ultrasound images of enrolled breast cancers from September 2017 to August 2020. We divided the data into in three groups as follows. Group I: estrogen receptor \pm , Group II: progesterone receptor \pm and Group III: human epidermal growth factor receptor2 \pm . Univariate and multivariate logistic regression analyses were used to analyze the clinical and ultrasound features related with biomarkers among these groups. A model to predict human epidermal growth factor receptor2+ subtype was then developed based on the results of multivariate regression analyses, and the efficacy was evaluated using the area under receiver operating characteristic curve, accuracy, sensitivity, specificity.
\end{abstract}

Results: The human epidermal growth factor receptor2+ subtype accounted for 138 cases (11.8\%) in the training set and 51 cases (10.1\%) in the test set. In the multivariate regression analysis, age $\leq 50$ years was an independent predictor of progesterone receptor $+(p=0.007)$, and posterior enhancement was a negative predictor of progesterone receptor + $(p=0.013)$ in Group Il; palpable axillary lymph node, round, irregular shape and calcifications were independent predictors of the positivity for human epidermal growth factor receptor-2 in Group III ( $p=0.001, p=0.007$, $p=0.010, p<0.001$, respectively). In Group I, shape was the only factor related to estrogen receptor status in the univariate analysis $(p<0.05)$. The area under receiver operating characteristic curve, accuracy, sensitivity, specificity of the model to predict human epidermal growth factor receptor2+ subtype breast cancer was $0.697,60.14 \%, 72.46 \%$, $58.49 \%$ and $0.725,72.06 \%, 64.71 \%, 72.89 \%$ in the training and test sets, respectively.

\footnotetext{
*Correspondence: sczhou@fudan.edu.cn; changcai_fuscc@hotmail.com

${ }^{\dagger}$ Jin Zhou and An-qi Jin contributed equally to this work

1 Department of Ultrasound, First Floor, Building 3, Fudan University

Shanghai Cancer Center, No. 270 Dong'an Road, Xuhui District, Shanghai,

China

Full list of author information is available at the end of the article
}

(C) The Author(s) 2021. Open Access This article is licensed under a Creative Commons Attribution 4.0 International License, which permits use, sharing, adaptation, distribution and reproduction in any medium or format, as long as you give appropriate credit to the original author(s) and the source, provide a link to the Creative Commons licence, and indicate if changes were made. The images or other third party material in this article are included in the article's Creative Commons licence, unless indicated otherwise in a credit line to the material. If material is not included in the article's Creative Commons licence and your intended use is not permitted by statutory regulation or exceeds the permitted use, you will need to obtain permission directly from the copyright holder. To view a copy of this licence, visit http://creativecommons.org/licenses/by/4.0/. The Creative Commons Public Domain Dedication waiver (http://creativeco mmons.org/publicdomain/zero/1.0/) applies to the data made available in this article, unless otherwise stated in a credit line to the data. 
Conclusions: Our study established a model to predict the human epidermal growth factor receptor2-positive subtype with moderate performance. And the results demonstrated that clinical and ultrasound features were significantly associated with biomarkers.

Keywords: Breast cancer, Estrogen receptor, Progesterone receptor, Human epidermal growth factor receptor-2, Ultrasound

\section{Introduction}

Breast cancer is a highly heterogenous tumor that has recently become the most common malignant tumor worldwide [1, 2]. The 2013 St. Gallen Consensus classified breast cancer into five subtypes according to the biomarker expression (estrogen receptor [ER], progesterone receptor $[\mathrm{PR}]$, human epidermal growth factor receptor-2 [HER2], and Ki67) evaluated using immunohistochemistry (IHC) [3]. Different breast cancer subtypes and biomarker expression of breast cancer are important prognostic factors $[4,5]$.

HER2+ breast cancer accounts for about $15-20 \%$ of all breast cancers [6]. HER2+ subtype (non-luminal) breast cancer is defined as ER-, PR-, HER2+, and has a high degree of malignancy and a poor prognosis, with a heterogeneous clinical and biological presentation. Hereafter, HER2+ subtype refers to HER2+ subtype (non-luminal). Chromosome 17 polyploidy, spatial and temporal heterogeneity of tumors lead to inaccurate assessment of HER2 status [7]. And HER2 score $2+$ on IHC require additional fluorescent in-situ hybridization (FISH) or chromogenic in-situ hybridization (CISH) testing to determine their status $[7,8]$. They adversely affect the diagnosis and treatment of HER2+ breast cancer. Currently, the diagnosis of breast cancer subtypes and biomarkers of breast cancer requires preoperative core-needle or postoperative pathology, which is an invasive and time-consuming process. If these could be obtained preoperatively and noninvasively, it would make the treatment process more timely, effective and precise.

In Asian women, ultrasound (US) is the method of choice for screening breast lesions since they have denser breast tissue and are relatively younger at the time of diagnosis [9-12]. Previous studies have found correlations between biomarkers (ER, PR, and HER2) and US features [13-15]. Xu et al. [15] found that the longest/ shortest size ratio $(>1)$, spiculate margin, and echo halo were related to ER and PR positivity. Additionally, Liu et al. [14] suggested that HER2 positivity was related to tumor blood supply and microcalcification. However, these studies utilized a relatively small number of cases and have correlated the relevant features directly with biomarkers (e.g., ER \pm , regardless of the status of PR, HER2). Thus, all three biomarkers had an impact on the US findings of breast cancer. When two biomarkers were known to be in the same status, studying the relationship between US features and one biomarker may be a feasible approach.

Previous studies $[2,16,17]$ revealed a correlation between the HER2+ subtype and US features, such as posterior enhancement or calcifications. However, many studies on conventional US features and breast cancer subtypes have been limited to correlation exploration [16-19], and fewer studies have built predictive models. In contrast to previous studies $[2,16,17]$ that directly correlated breast cancer subtypes with relevant features, we aimed to build a predictive model for the HER2+ subtype using relevant features of three biomarkers and evaluate its performance.

The purpose of this study was to evaluate the associated clinical and US features of ER, PR, and HER2 when two biomarkers were in known same status, and then develop a predictive model for the HER2+ subtype. To the best of our knowledge, this study is the first to identify clinical and US features associated with ER, PR, and HER-2 status when two biomarkers were known to be in the same status.

\section{Methods \\ Study population}

This study included patients who underwent preoperative breast US in projects funded by the National Natural Science Foundation from September 2017 to August 2020. Patients with the following characteristics were included: (1) evident lesions on preoperative US images, and multiple US images of breast tumors; (2) breast cancers diagnosed by core needle biopsy or surgical pathology; and (3) the absence of treatment, prior to US. Patients with the following characteristics were excluded: (1) any treatment, such as radiotherapy, before US examination; (2) invisible or obscure lesions on the US examinations; or (3) incomplete clinical data.

This retrospective study was approved by the institutional ethics committee of our center. The requirement for informed consent was waived due to the retrospective nature of the study. We randomized the enrolled data into a training set (1169 cases) and a test set (501 cases) by a $7: 3$ ratio.

As mentioned previously, no article considered the possible interaction of biomarkers on the ultrasound feature 
Table 1 Clinicopathological characteristics and baseline of all cases, training set and test set

\begin{tabular}{|c|c|c|c|c|}
\hline Characteristics & $\begin{array}{l}\text { All cases } \\
(\mathrm{N}=1670)\end{array}$ & $\begin{array}{l}\text { Training set } \\
(\mathrm{N}=1169)\end{array}$ & $\begin{array}{l}\text { Test set } \\
(\mathrm{N}=501)\end{array}$ & $P$ value \\
\hline Age (year) & $53.1[45,61]$ & $53[45,61]$ & $53[46,61]$ & 0.604 \\
\hline tumor size (mm) & $21.0[15,26]$ & $20.0[15,26]$ & $20.0[15,26]$ & 0.393 \\
\hline BMI value & $23.3[21.4,25.4]$ & $23.3[21.5,25.4]$ & $23.23[21.2,25.1]$ & 0.335 \\
\hline Menopause & & & & 0.724 \\
\hline No & $769(46.0)$ & $535(45.8)$ & $234(46.7)$ & \\
\hline Yes & $901(54.0)$ & $634(54.2)$ & $267(53.3)$ & \\
\hline Breast cancer family history & & & & 0.566 \\
\hline No & $1610(96.4)$ & $1125(96.2)$ & $485(96.8)$ & \\
\hline Yes & $60(3.6)$ & $44(3.8)$ & $16(3.2)$ & \\
\hline Palpable ALN & & & & 0.534 \\
\hline No & $1348(80.7)$ & $939(80.3)$ & $409(81.6)$ & \\
\hline Yes & $322(19.3)$ & $230(19.7)$ & $92(18.4)$ & \\
\hline \multicolumn{5}{|l|}{ US ALN } \\
\hline No & $1031(61.7)$ & $712(60.9)$ & $319(63.7)$ & 0.287 \\
\hline Yes & $639(38.3)$ & $457(39.1)$ & $182(36.3)$ & \\
\hline \multicolumn{5}{|l|}{ Shape } \\
\hline Oval & $90(5.4)$ & $67(5.7)$ & $23(4.6)$ & 0.259 \\
\hline Round & $62(3.7)$ & $48(4.1)$ & $14(2.8)$ & \\
\hline Irregular & $1518(90.9)$ & $1054(90.2)$ & $464(92.6)$ & \\
\hline Orientation & & & & 0.860 \\
\hline Parallel & $1048(62.8)$ & $732(62.6)$ & $316(63.1)$ & \\
\hline Not parallel & $622(37.2)$ & $437(37.4)$ & $185(36.9)$ & \\
\hline Margin & & & & 0.690 \\
\hline Circumscribed & $37(2.2)$ & $27(2.3)$ & $10(2.0)$ & \\
\hline Not circumscribed & $1633(97.8)$ & $1142(97.7)$ & $491(98.0)$ & \\
\hline Boundary & & & & 0.168 \\
\hline Abrupt & $1068(64.0)$ & $760(65.0)$ & $308(61.5)$ & \\
\hline Halo & $602(36.0)$ & $409(35.0)$ & $193(38.5)$ & \\
\hline Echo pattern & & & & 0.945 \\
\hline Hypoechoic & $1483(88.8)$ & $1041(89.1)$ & $442(88.2)$ & \\
\hline Isoechoic & $57(3.4)$ & $40(3.4)$ & $17(3.4)$ & \\
\hline Complex & $103(6.2)$ & $70(6.0)$ & $33(6.6)$ & \\
\hline Hyperechoic & $27(1.6)$ & $18(1.5)$ & $9(1.8)$ & \\
\hline Posterior acoustic features & & & & 0.379 \\
\hline No & $504(30.2)$ & $350(30.0)$ & $154(30.7)$ & \\
\hline Enhancement & $560(33.5)$ & $393(33.6)$ & $167(33.4)$ & \\
\hline Shadowing & $539(32.3)$ & 385 (32.9) & $154(30.7)$ & \\
\hline Combined & $67(4.0)$ & $41(3.5)$ & $26(5.2)$ & \\
\hline Calcifications & & & & 0.010 \\
\hline No & $826(49.5)$ & $554(47.4)$ & $272(54.3)$ & \\
\hline Yes & $844(50.5)$ & $615(52.6)$ & $229(45.7)$ & \\
\hline Vascular degree & & & & 0.973 \\
\hline 0 & $226(13.5)$ & $160(13.7)$ & $66(13.2)$ & \\
\hline । & $275(16.5)$ & $190(16.2)$ & $85(17.0)$ & \\
\hline$\|$ & $766(45.9)$ & $535(45.8)$ & $231(46.1)$ & \\
\hline III & $403(24.1)$ & $284(24.3)$ & $119(23.7)$ & \\
\hline
\end{tabular}

$B M I$ body mass index, $A L N$ axillary lymph node, US ultrasound 


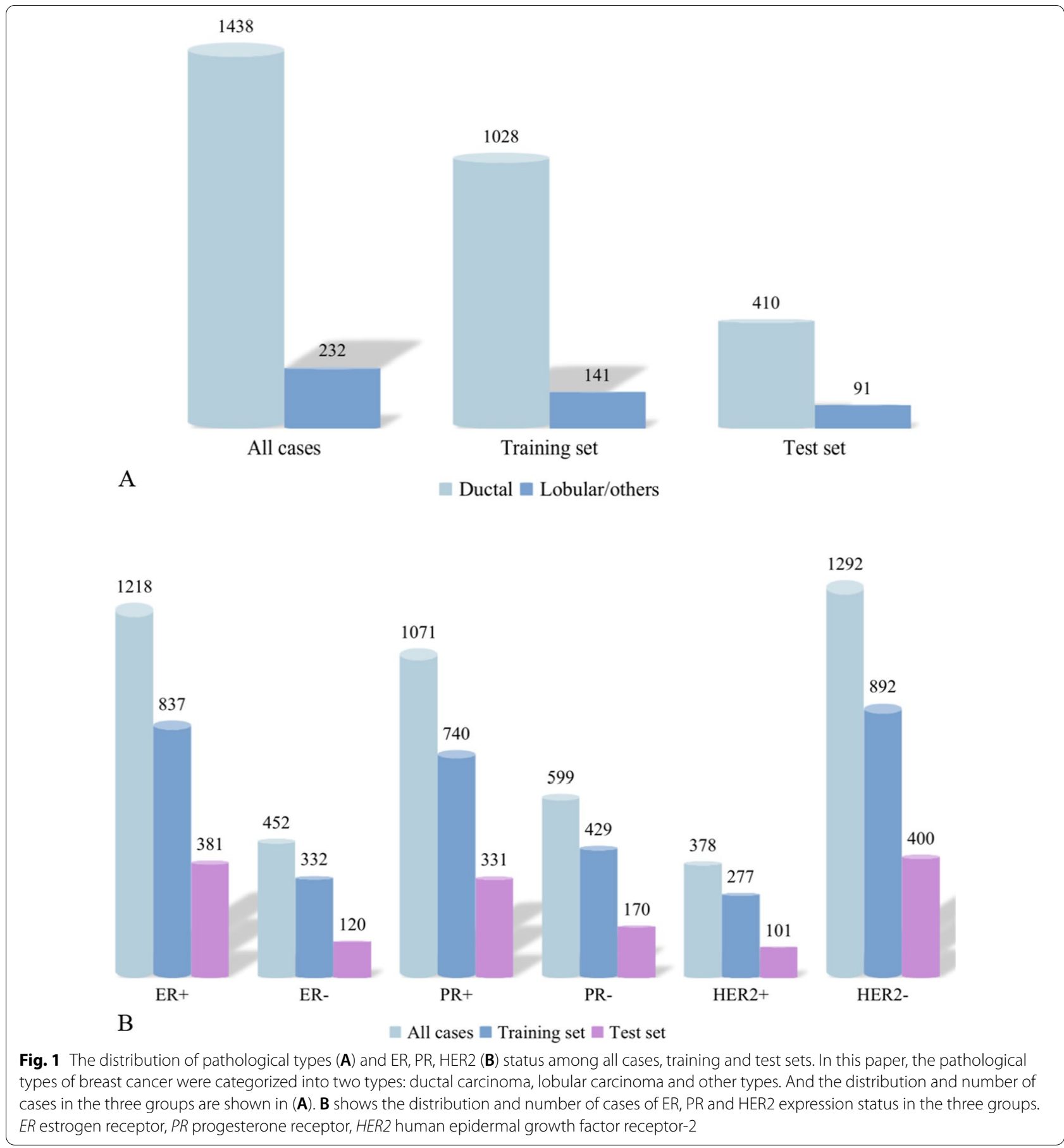

of breast cancers. Thus, our study made two of the three markers in identical status between two groups to analyze whether the remaining markers have a relationship with ultrasound features. Since no case presented ERand PR+ and only 55 cases were ER+, PR-, HER2+, only the following classification of cases could be studied in this study. To facilitate follow-up studies and promote understanding, the cases were grouped as follows, Group I: ER+ vs ER - (PR and HER2 negative), Group II: PR+ vs PR - (ER+, HER2-), and Group III: HER2+ vs HER2(ER and PR negative). 
Table 2 ER and clinical and ultrasound features in Group I from the training set

\begin{tabular}{|c|c|c|c|c|}
\hline \multirow[t]{2}{*}{ Clinical and ultrasound features } & \multicolumn{2}{|l|}{ Group I } & \multicolumn{2}{|c|}{ Univariate analysis } \\
\hline & $\begin{array}{l}\text { ER- (PR-, HER2-) } \\
(\mathrm{N}=194)\end{array}$ & $\begin{array}{l}E R+(P R-, \text { HER2 }-) \\
(N=62)\end{array}$ & $X^{2}$ value & $P$ value \\
\hline Age (year) & & & 3.719 & 0.054 \\
\hline$\leq 50$ & $83(42.8)$ & $18(29.0)$ & & \\
\hline$>50$ & $111(57.2)$ & $44(71.0)$ & & \\
\hline Palpable ALN & & & 0.818 & 0.366 \\
\hline No & $149(76.8)$ & $51(82.3)$ & & \\
\hline Yes & $45(23.2)$ & $11(17.7)$ & & \\
\hline US ALN & & & 0.979 & 0.323 \\
\hline No & $105(54.1)$ & $38(61.3)$ & & \\
\hline Yes & $89(45.9)$ & $24(38.7)$ & & \\
\hline Breast cancer family history & & & 0.391 & 0.534 \\
\hline No & $184(94.8)$ & $60(96.8)$ & & \\
\hline Yes & $10(5.2)$ & $2(3.2)$ & & \\
\hline Menopause & & & 2.374 & 0.123 \\
\hline No & $84(43.3)$ & $20(32.3)$ & & \\
\hline Yes & $110(56.7)$ & $42(67.7)$ & & \\
\hline $\mathrm{BMI}\left(\mathrm{kg} / \mathrm{m}^{2}\right)$ & & & 2.979 & 0.225 \\
\hline$<18$ & $3(1.5)$ & $3(4.8)$ & & \\
\hline $18-24$ & $119(61.4)$ & $33(53.2)$ & & \\
\hline$>24$ & $72(37.1)$ & $26(42.0)$ & & \\
\hline Tumor size (mm) & & & 1.958 & 0.162 \\
\hline$\leq 20$ & $29(14.9)$ & $14(22.6)$ & & \\
\hline$>20$ & $165(85.1)$ & $48(77.4)$ & & \\
\hline Shape & & & 8.255 & $0.016^{*}$ \\
\hline Oval & $28(14.4)$ & $1(1.6)$ & & \\
\hline Round & $7(3.6)$ & $4(6.5)$ & & \\
\hline Irregular & $159(82.0)$ & $57(91.9)$ & & \\
\hline Orientation & & & 2.049 & 0.152 \\
\hline Parallel & $126(64.9)$ & $34(54.8)$ & & \\
\hline Not parallel & $68(35.1)$ & $28(45.2)$ & & \\
\hline Margin & & & 0.191 & 0.662 \\
\hline Circumscribed & $5(2.6)$ & $1(1.6)$ & & \\
\hline Not circumscribed & $189(97.4)$ & $61(98.4)$ & & \\
\hline Boundary & & & 3.434 & 0.064 \\
\hline Abrupt & $140(72.2)$ & $37(59.7)$ & & \\
\hline Halo & $54(27.8)$ & $25(40.3)$ & & \\
\hline Echo pattern & & & 2.338 & 0.505 \\
\hline Hypoechoic & $175(90.2)$ & $59(95.2)$ & & \\
\hline Isoechoic & $2(1.0)$ & $1(1.6)$ & & \\
\hline Complex & $15(7.8)$ & $2(3.2)$ & & \\
\hline Hyperechoic & $2(1.0)$ & $0(0.0)$ & & \\
\hline Posterior acoustic features & & & 6.378 & 0.095 \\
\hline No & $47(24.2)$ & $14(22.6)$ & & \\
\hline Enhancement & $106(54.7)$ & $26(41.9)$ & & \\
\hline Shadowing & $34(17.5)$ & $20(32.3)$ & & \\
\hline Combined & $7(3.6)$ & $2(3.2)$ & & \\
\hline Calcifications & & & 0.304 & 0.581 \\
\hline No & $111(57.2)$ & $33(53.2)$ & & \\
\hline
\end{tabular}


Table 2 (continued)

\begin{tabular}{|c|c|c|c|c|}
\hline \multirow[t]{2}{*}{ Clinical and ultrasound features } & \multicolumn{2}{|l|}{ Group I } & \multicolumn{2}{|c|}{ Univariate analysis } \\
\hline & $\begin{array}{l}\text { ER- }(P R-, \text { HER2- }) \\
(N=194)\end{array}$ & $\begin{array}{l}\mathrm{ER}+(\mathrm{PR}-, \mathrm{HER} 2-) \\
(\mathrm{N}=62)\end{array}$ & $X^{2}$ value & $P$ value \\
\hline Yes & $83(42.8)$ & $29(46.8)$ & & \\
\hline Vascular degree & & & 0.174 & 0.986 \\
\hline 0 & $27(13.9)$ & $9(14.5)$ & & \\
\hline I & $25(12.9)$ & $9(14.5)$ & & \\
\hline$\|$ & $86(44.3)$ & $27(43.6)$ & & \\
\hline III & 56 (28.9) & $17(27.4)$ & & \\
\hline
\end{tabular}

$E R$ estrogen receptor, $P R$ progesterone receptor, $H E R 2$ human epidermal growth factor receptor-2, $B M I$ body mass index, ALN axillary lymph node, US ultrasound

\section{Pathology and immunohistochemistry analysis}

Data regarding the age, BMI (body mass index), menopause, palpable axillary lymph node (ALN), breast cancer family history, US ALN, pathological type, histological grade, and ER, PR, HER2 status were collected from the medical record system. The positivity of ER or PR is defined as $\geq 1 \%$ on IHC staining [3]. The positivity of HER2 is defined by any of following test results: (1) IHC $3+$, or complete and strong member staining of $>30 \%$ of invasive cancer cells; (2) FISH measurement of HER2/CEP17 ratio of $>2.2 / 2.0$; and (3) $\mathrm{CISH}$ of a HER2 gene copy number of $>6.0$ signals per nucleus [8].

\section{US images assessment}

Most breast US images were obtained using the SuperSonica Aixplorer US scanner (SuperSonic Imagine S.A., Aix-en-Provence, France) equipped with a $7-15 \mathrm{MHz}$ linear array transducer. Other breast US images were obtained using the Mindray Resona 5S US scanner (Shenzhen Mindray Bio-Medical Electronics Co., Ltd., Shenzhen, China) equipped with a $5-14 \mathrm{MHz}$ linear array transducer. The imaging acquisition standards were as follows: 12 conventional US images were captured starting with the largest cross-section of the tumor at equal intervals in a $180^{\circ}$ clockwise range. Suspicious breast lesions were measured at the maximal diameter on US images.

The US features were assessed according to the Breast Imaging-Reporting and Data System [20, 21], including shape, orientation, margins, boundary, echo pattern, calcification, and posterior acoustic features. Additionally, vascularity was assessed according to Adler's index (0, I, II, or III) [22]. All US images were reviewed by two US specialists who were blinded to the patients' pathological results. If the two reviewers disagreed, a consensus was reached after their discussion.

\section{Statistical analysis}

Data analysis was performed using SPSS version 20 (IBM Corp, Armonk, NY, USA). The data were randomly divided into the training and test sets using random numbers. Normally distributed data, assessed using the Kolmogorov-Smirnov test, were expressed as mean \pm standard deviation. And non-normally distributed data were expressed as median with interquartile range. Categorical variables were analyzed using the Chisquare or Fisher's exact test. Multivariate logistic regression analysis (backward stepwise) was used to study the association between clinical and US features and the three biomarkers. The model was built using $\mathrm{R}$ software (version 4.1.0, $\mathrm{R}$ Foundation for Statistical Computing, Vienna, Austria) based on the independent predictors from the multivariate regression analysis, and the diagnostic efficacy of the model was evaluated using the area under the receiver operating characteristic curve (AUC), accuracy (ACC), sensitivity (SENS) and specificity (SPEC). Statistical significance was set at $\mathrm{P}<0.05$.

\section{Results}

Clinical and pathological characteristics

The study enrolled 1670 breast cancer cases (1662 female patients) with a mean age of 53.1 years (range 22-95 years) and mean tumor size of $21.0 \mathrm{~mm}$ (range 6-68 mm). The training set had a mean age of 53 years (range 22-95 years) and mean tumor size of $20 \mathrm{~mm}$ (range 5-68 mm), while the test set had a mean age of 53 years (range $28-87$ years) and mean tumor size of $20 \mathrm{~mm}$ (range 6-56 mm). The two sets were not statistically different at the baseline of clinical and US features (excluding calcifications). All details are shown in Table 1 and Fig. 1.

\section{Relationship among biomarkers, clinical and US features in group I-III from the training set}

The following groups were formed as previously described, Group I: ER + vs ER- (PR and HER2 negative), Group II: PR+ vs PR- (ER+, HER2-), and Group III: HER2+ vs HER2 - (ER and PR negative). 
Table 3 PR and clinical and ultrasound features in Group II from the training set

\begin{tabular}{|c|c|c|c|c|c|c|}
\hline \multirow[t]{2}{*}{ Clinical and ultrasound features } & \multicolumn{2}{|l|}{ Group II } & \multicolumn{2}{|c|}{ Univariate analysis } & \multicolumn{2}{|l|}{ Multivariate analysis } \\
\hline & $\begin{array}{l}\text { PR- (ER }+, \text { HER2-) } \\
(\mathrm{N}=62)\end{array}$ & $\begin{array}{l}\mathrm{PR}+(\mathrm{ER}+, \mathrm{HER} 2-) \\
(\mathrm{N}=636)\end{array}$ & $X^{2}$ Value & $P$ value & OR $(95 \% \mathrm{Cl})$ & $P$ value \\
\hline Age (year) & & & 7.747 & $0.005^{*}$ & & $0.007^{*}$ \\
\hline$\leq 50$ & $18(29.0)$ & $302(47.5)$ & & & $2.204(1.238-3.924)$ & \\
\hline$>50$ & $44(71.0)$ & $334(52.5)$ & & & 1 & \\
\hline Palpable ALN & & & 0.345 & 0.557 & & \\
\hline No & $51(82.3)$ & $541(85.1)$ & & & & \\
\hline Yes & $11(17.7)$ & $95(14.9)$ & & & & \\
\hline US ALN & & & 1.431 & 0.232 & & \\
\hline No & $38(61.3)$ & $437(68.7)$ & & & & \\
\hline Yes & $24(38.7)$ & $199(31.3)$ & & & & \\
\hline Breast cancer family history & & & 0.001 & 0.974 & & \\
\hline No & $60(96.8)$ & $615(96.7)$ & & & & \\
\hline Yes & $2(3.2)$ & $21(3.3)$ & & & & \\
\hline Menopause & & & 6.158 & $0.013^{*}$ & & \\
\hline No & $20(32.3)$ & $310(48.7)$ & & & & \\
\hline Yes & $42(67.7)$ & $326(51.3)$ & & & & \\
\hline $\mathrm{BMI}\left(\mathrm{kg} / \mathrm{m}^{2}\right)$ & & & 1.391 & 0.499 & & \\
\hline$<18$ & $3(4.8)$ & $15(2.4)$ & & & & \\
\hline $18-24$ & $33(53.2)$ & $351(55.2)$ & & & & \\
\hline$>24$ & $26(42.0)$ & $270(42.4)$ & & & & \\
\hline Tumor size (mm) & & & 0.002 & 0.964 & & \\
\hline$\leq 20$ & $14(22.6)$ & $142(22.3)$ & & & & \\
\hline$>20$ & $48(77.4)$ & $494(77.7)$ & & & & \\
\hline Shape & & & 1.664 & 0.435 & & \\
\hline Oval & $1(1.6)$ & $29(4.6)$ & & & & \\
\hline Round & $4(6.5)$ & $28(4.4)$ & & & & \\
\hline Irregular & $57(91.9)$ & $579(91.0)$ & & & & \\
\hline Orientation & & & 0.853 & 0.356 & & \\
\hline Parallel & $34(54.8)$ & $387(60.8)$ & & & & \\
\hline Not parallel & $28(45.2)$ & $249(39.2)$ & & & & \\
\hline Margin & & & 0.140 & 0.708 & & \\
\hline Circumscribed & $1(1.6)$ & $15(2.4)$ & & & & \\
\hline Not circumscribed & $61(98.4)$ & $621(97.6)$ & & & & \\
\hline Lesion boundary & & & 0.007 & 0.934 & & \\
\hline Abrupt & $37(59.7)$ & $383(60.2)$ & & & & \\
\hline Halo & $25(40.3)$ & $253(39.8)$ & & & & \\
\hline Echo pattern & & & 3.643 & 0.303 & & \\
\hline Hypoechoic & $59(95.2)$ & $554(87.1)$ & & & & \\
\hline Isoechoic & $1(1.6)$ & $28(4.4)$ & & & & \\
\hline Complex & $2(3.2)$ & $43(6.8)$ & & & & \\
\hline Hyperechoic & $0(0.0)$ & $11(1.7)$ & & & & \\
\hline Posterior acoustic features & & & & & & $0.039^{*}$ \\
\hline No features & $14(22.6)$ & $213(33.5)$ & 8.951 & $0.03^{*}$ & 1 & \\
\hline Enhancement & $26(41.9)$ & $158(24.8)$ & & & $0.418(0.211-0.830)$ & $0.013^{*}$ \\
\hline Shadowing & $20(32.3)$ & $246(38.7)$ & & & $0.876(0.430-1.785)$ & 0.715 \\
\hline Combined & $2(3.2)$ & $19(3.0)$ & & & $0.453(0.115-2.632)$ & 0.453 \\
\hline Calcification & & & 0.032 & 0.859 & & \\
\hline No & $33(53.2)$ & $331(52.0)$ & & & & \\
\hline
\end{tabular}


Table 3 (continued)

\begin{tabular}{|c|c|c|c|c|c|c|}
\hline \multirow[t]{2}{*}{ Clinical and ultrasound features } & \multicolumn{2}{|l|}{ Group II } & \multicolumn{2}{|c|}{ Univariate analysis } & \multicolumn{2}{|c|}{ Multivariate analysis } \\
\hline & $\begin{array}{l}\mathrm{PR}-(\mathrm{ER}+, \mathrm{HER} 2-) \\
(\mathrm{N}=62)\end{array}$ & $\begin{array}{l}\mathrm{PR}+(\mathrm{ER}+, \mathrm{HER} 2-) \\
(\mathrm{N}=636)\end{array}$ & $X^{2}$ Value & $P$ value & OR $(95 \% \mathrm{Cl})$ & $P$ value \\
\hline Yes & $29(46.8)$ & $305(48.0)$ & & & & \\
\hline Vascular degree & & & 0.960 & 0.811 & & \\
\hline 0 & $9(14.5)$ & 99 (15.6) & & & & \\
\hline I & $9(14.5)$ & $110(17.3)$ & & & & \\
\hline$\|$ & $27(43.6)$ & $285(44.8)$ & & & & \\
\hline III & 17 (27.4) & $142(22.3)$ & & & & \\
\hline
\end{tabular}

ER estrogen receptor, $P R$ progesterone receptor, $H E R 2$ human epidermal growth factor receptor-2, BMI body mass index, $A L N$ axillary lymph node, US ultrasound

In Group I, shape was the only factor related to ER status in the univariate analysis $(\mathrm{p}<0.05)$. Oval shape was more frequent in ER-; additionally, older patients (age $>50$ years) were more likely to express $\mathrm{ER}+($ Table 2). No multivariate regression analysis was performed because there was only one significant factor in the univariate analysis.

In Group II, age, menopause status and posterior acoustic features were related to PR status in the univariate analysis $(\mathrm{p}<0.05)$. Age $\leq 50$ years was an independent predictor of PR+ (OR 2.204, 95\% CI 1.238-3.924, $\mathrm{p}=0.007$ ), and younger patients were 2.204 more likely than older patients to express $\mathrm{PR}+$; additionally, posterior enhancement was a negative predictor of $\mathrm{PR}+(\mathrm{OR}$ $0.418,95 \%$ CI $0.211-0.830, \mathrm{p}=0.013$ ), and tumors with posterior enhancement were 0.418 times more likely to exhibit PR+ than tumors with no change in posterior echogenicity (Table 3).

In Group III, palpable ALN, US ALN, calcifications, shape, and posterior acoustic features were related to HER2 status in the univariate analysis $(\mathrm{p}<0.05)$. Palpable ALN; round, irregular shape; and calcifications were independent predictors of HER2+ (OR 2.319, 95\% CI 1.381-3.895 p=0.001; OR 7.491, 95\% CI 1.715-32.724, $\mathrm{p}=0.007 ;$ OR 3.786, 95\% CI 1.369-10.470, $\mathrm{p}=0.010$; OR 3.346, 95\% CI 2.051-5.459, p $<0.001$, respectively). In breast cancers, round and irregular shapes were 7.491 and 3.786 times more likely to express HER2+ than oval shapes, respectively; the presence of calcifications was 3.346 times more prone to express HER2+ than those without calcifications; and the presence of palpable ALN was 2.319 times more likely to express HER2+ than those without palpable ALN (Table 4).

All details are illustrated in Tables 2, 3 and 4.

\section{Performance of prediction model for the HER2+ subtype (non-luminal) in training and test sets}

The HER2+ subtype accounted for 138 cases (11.8\%) in the training set and 51 cases $(10.1 \%)$ in the test set.
Univariate or multivariate logistic regression analyses of Groups I-III were performed to obtain the relevant features of ER, PR, HER2 (i.e. age, palpable ALN, posterior acoustic features, calcifications, and shape), and to develop a model to predict the HER2+ subtype. The diagnostic efficacy of the model to predict the HER2+ subtype in the training set was AUC 0.697, ACC 60.14\%, SENS 72.46\%, SPEC 58.49\%; and the best cutoff was 0.1028786 (Fig. 2). The efficacy of the model in the test set was AUC 0.725, ACC 72.06\%, SENS 64.71\%, SPEC 72.89\%; and the best cutoff was 0.1321628 (Fig. 3).

\section{Discussion}

Preoperative prediction of biomarkers and breast cancer subtypes can improve the efficiency of the treatment process. It remains unknown that the relationship between clinical and US features and the remaining biomarker, when maintain two of ER, PR, and HER2 in same status. After the matching analysis, the results of this study suggested that, regarding the US features of breast cancers, PR status was mainly reflected by the posterior acoustic features, and HER2 status by the tumor shape and presence of calcifications. None of the US features were found to be independent predictors of ER status when both PR and HER2 were known negative. This study established a predictive model with moderate diagnostic power for predicting the HER2+ subtype.

Biomarker status and molecular subtypes play an important role in the clinical management, outcome and prognosis. For example, ER+/HER2- breast cancer has a better prognosis and requires only endocrine therapy, while the HER2+ subtype requires chemotherapy. The relationship between US features and biomarkers of breast cancer was investigated to better distinguish molecular subtypes before surgery. In previous studies of ER+/ER - breast cancer (regardless of PR and HER2 status), Kim et al. [23] suggested that hypoechoic and complex echo patterns were significantly related to ER and PR negativity; the study by $\mathrm{Xu}$ et al. showed 
Table 4 HER2 and clinical and ultrasound features in Group III from the training set

\begin{tabular}{|c|c|c|c|c|c|c|}
\hline \multirow[t]{2}{*}{ Clinical and ultrasound features } & \multicolumn{2}{|l|}{ Group III } & \multicolumn{2}{|c|}{ Univariate analysis } & \multicolumn{2}{|l|}{ Multivariate analysis } \\
\hline & $\begin{array}{l}\text { HER2 }-(E R-, P R-) \\
(N=194)\end{array}$ & $\begin{array}{l}\text { HER2 + (ER-, PR-) } \\
(\mathrm{N}=138)\end{array}$ & $X^{2}$ Value & $P$ value & OR $(95 \% \mathrm{Cl})$ & $P$ value \\
\hline Age (year) & & & 2.161 & 0.142 & & \\
\hline$\leq 50$ & $83(42.8)$ & $48(34.8)$ & & & & \\
\hline$>50$ & $111(57.2)$ & $90(65.2)$ & & & & \\
\hline Palpable ALN & & & 7.429 & $0.006^{*}$ & & $0.001^{*}$ \\
\hline No & $149(76.8)$ & $87(63.0)$ & & & 1 & \\
\hline Yes & $45(23.2)$ & $51(37.0)$ & & & $2.319(1.381-3.895)$ & \\
\hline US ALN & & & 5.922 & $0.015^{*}$ & & \\
\hline No & $105(54.1)$ & $56(40.6)$ & & & & \\
\hline Yes & $89(45.9)$ & $82(59.4)$ & & & & \\
\hline Breast cancer family history & & & 1.016 & 0.313 & & \\
\hline No & $184(94.8)$ & $134(97.1)$ & & & & \\
\hline Yes & $10(5.2)$ & $4(2.9)$ & & & & \\
\hline Menopause & & & 2.442 & 0.118 & & \\
\hline No & $84(43.3)$ & $48(34.8)$ & & & & \\
\hline Yes & $110(56.7)$ & $90(65.2)$ & & & & \\
\hline $\mathrm{BMI}\left(\mathrm{kg} / \mathrm{m}^{2}\right)$ & & & 1.075 & 0.584 & & \\
\hline$<18$ & $3(1.5)$ & $2(1.4)$ & & & & \\
\hline $18-24$ & $119(61.4)$ & $77(55.8)$ & & & & \\
\hline$>24$ & $72(37.1)$ & $59(42.8)$ & & & & \\
\hline Tumor size (mm) & & & 0.180 & 0.671 & & \\
\hline$\leq 20$ & $29(14.9)$ & $23(16.7)$ & & & & \\
\hline$>20$ & $165(85.1)$ & $115(83.3)$ & & & & \\
\hline Shape & & & 10.710 & $0.005^{*}$ & & $0.015^{*}$ \\
\hline Oval & $28(14.4)$ & $5(3.6)$ & & & 1 & \\
\hline Round & $7(3.6)$ & $7(5.1)$ & & & $7.491(1.715-32.724)$ & $0.007^{*}$ \\
\hline Irregular & $159(82.0)$ & $126(91.3)$ & & & $3.786(1.369-10.470)$ & $0.010^{*}$ \\
\hline Orientation & & & 0.035 & 0.851 & & \\
\hline Parallel & $126(64.9)$ & $91(65.9)$ & & & & \\
\hline Not parallel & $68(35.1)$ & $47(34.1)$ & & & & \\
\hline Margin & & & 0.032 & 0.859 & & \\
\hline Circumscribed & $5(2.6)$ & $4(2.9)$ & & & & \\
\hline Not circumscribed & $189(97.4)$ & $134(97.1)$ & & & & \\
\hline Boundary & & & 0.251 & 0.616 & & \\
\hline Abrupt & $140(72.2)$ & $103(74.6)$ & & & & \\
\hline Halo & $54(27.8)$ & $35(25.4)$ & & & & \\
\hline Echo pattern & & & 4.203 & 0.240 & & \\
\hline Hypoechoic & $175(90.2)$ & $129(93.5)$ & & & & \\
\hline Isoechoic & $2(1.0)$ & $2(1.4)$ & & & & \\
\hline Complex & $15(7.8)$ & $4(2.9)$ & & & & \\
\hline Hyperechoic & $2(1.0)$ & $3(2.2)$ & & & & \\
\hline Posterior acoustic features & & & 9.179 & $0.027^{*}$ & & \\
\hline No & $47(24.2)$ & 35 (25.4) & & & & \\
\hline Enhancement & $106(54.7)$ & $56(40.6)$ & & & & \\
\hline Shadowing & $34(17.5)$ & $42(30.4)$ & & & & \\
\hline Combined & $7(3.6)$ & $5(3.6)$ & & & & \\
\hline Calcifications & & & 24.579 & $<0.001^{*}$ & & $<0.001^{*}$ \\
\hline No & $111(57.2)$ & $41(29.7)$ & & & 1 & \\
\hline
\end{tabular}


Table 4 (continued)

\begin{tabular}{|c|c|c|c|c|c|c|}
\hline \multirow[t]{2}{*}{ Clinical and ultrasound features } & \multicolumn{2}{|l|}{ Group III } & \multicolumn{2}{|c|}{ Univariate analysis } & \multicolumn{2}{|c|}{ Multivariate analysis } \\
\hline & $\begin{array}{l}\text { HER2 }-(E R-, P R-) \\
(N=194)\end{array}$ & $\begin{array}{l}\text { HER2 + (ER-, PR-) } \\
(\mathrm{N}=138)\end{array}$ & $x^{2}$ Value & $P$ value & OR $(95 \% \mathrm{Cl})$ & $P$ value \\
\hline Yes & $83(42.8)$ & $97(70.3)$ & & & $3.346(2.051-5.459)$ & \\
\hline Vascular degree & & & 4.973 & 0.174 & & \\
\hline 0 & $27(13.9)$ & $12(8.7)$ & & & & \\
\hline I & $25(12.9)$ & $23(16.7)$ & & & & \\
\hline$\|$ & $86(44.3)$ & $72(52.2)$ & & & & \\
\hline III & $56(28.9)$ & $31(22.4)$ & & & & \\
\hline
\end{tabular}

$E R$ estrogen receptor, $P R$ progesterone receptor, $H E R 2$ human epidermal growth factor receptor-2, $B M I$ body mass index, $A L N$ axillary lymph node, US ultrasound

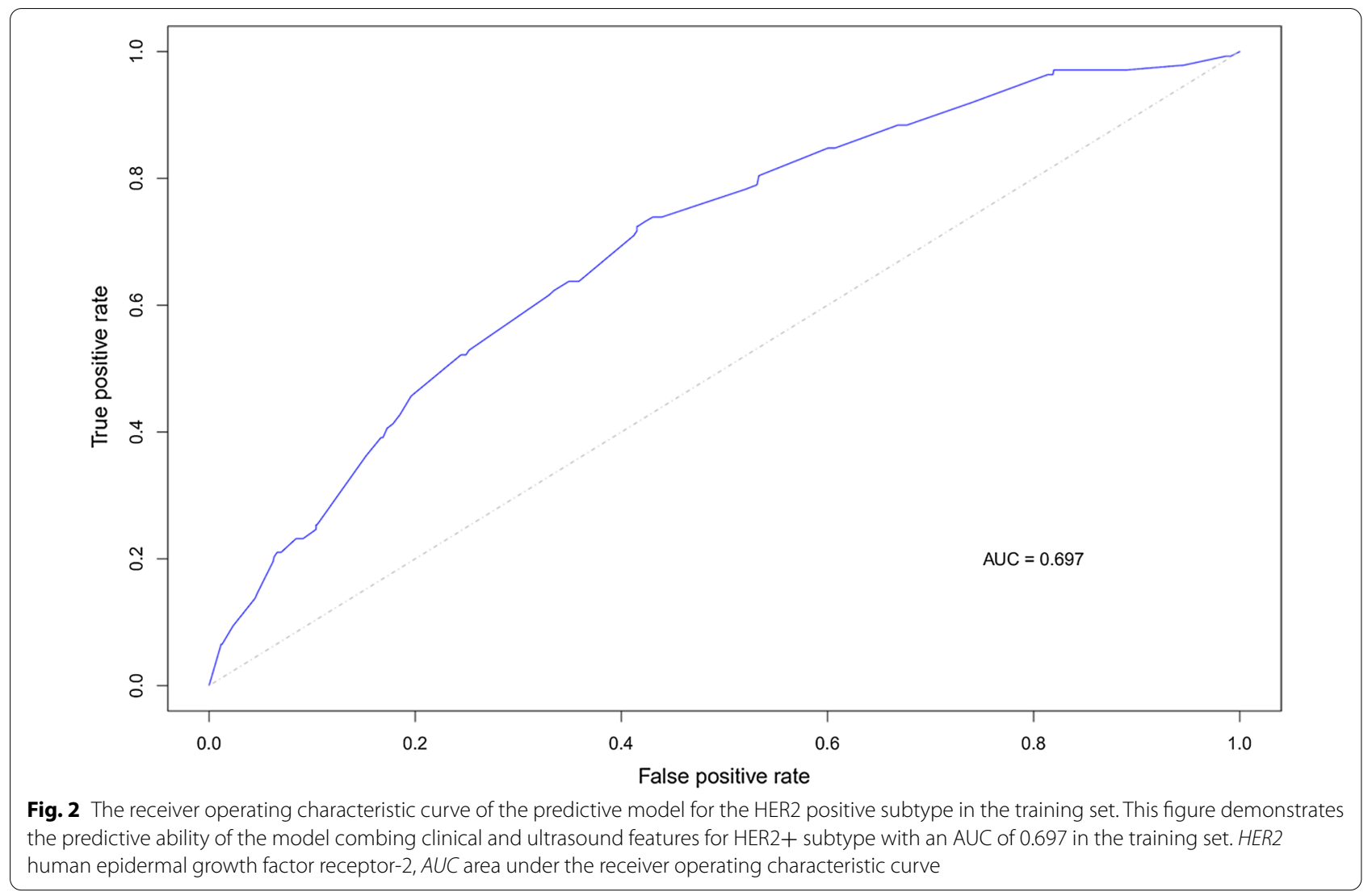

an association between ER and PR positivity and echo halo [15]. Inconsistent with previous studies [15, 23], we found no US feature to be an independent predictor of ER status in Group I. However, although tumor's shape did not correlate with ER status in the multivariate regression analysis, but it was still evident that ERtumors showed a much higher percentage of oval shapes than ER+ tumors (14.4\% vs $1.6 \%$ in Group I, $9.9 \%$ vs $4.1 \%$ in the training set). Contrary to a previous study [24], this study suggested that age was not relate with ER in Group I. Additionally, older patients with breast cancer were more frequent in ER+. Although the age structure of the included cases in this study was generally consistent with the study by Zhu et al. [24] (age $<50$ years: 39.5\% vs $44.8 \%$ ), the proportion of $E R+$ of both tumors and younger patients (age $<50$ years) in the training set was relatively lower in our study $(71.5 \%$ vs $78.4 \%, 74.5 \%$ vs $80.3 \%)$. This may be the reason for the different results.

In Group II, younger age was an independent predictor $\mathrm{PR}+(\mathrm{p}<0.005)$, consistent with the study by Zhu et al. [24]. Besides, this study suggested that younger patients were approximately twice more likely than older patients 


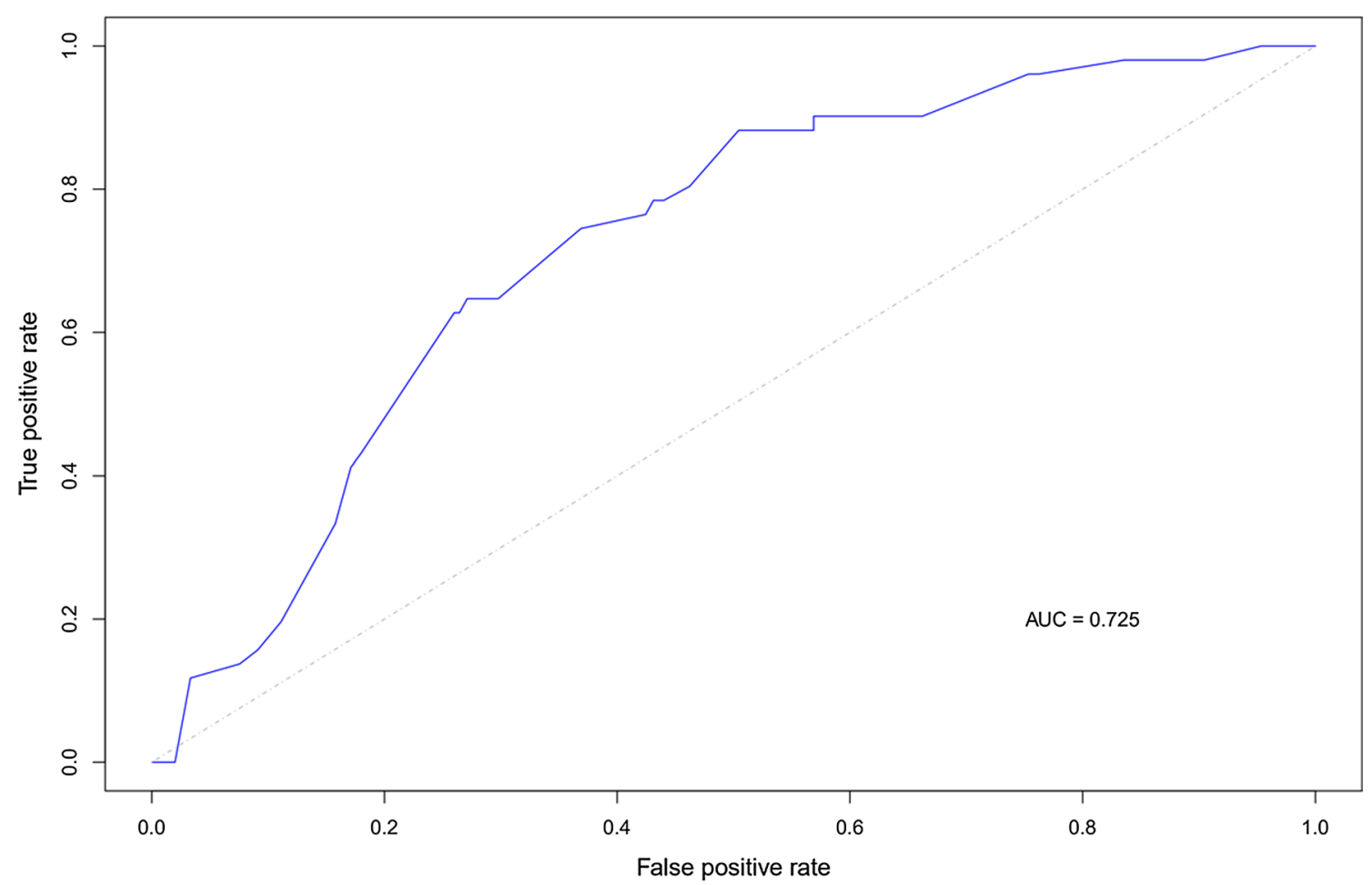

Fig. 3 The receiver operating characteristic curve of the predictive model for the HER2 positive subtype in the test set. This figure shows that the model with combined clinical and ultrasound features had moderate predictive power for HER2+ subtype, with an AUC of 0.725 in the test set. HER2 human epidermal growth factor receptor-2, AUC area under the receiver operating characteristic curve

to express PR+. Tumors with higher histological grade have faster cell proliferation, increased cell and necrotic components, less fibrous tissue, and increased tissue structure uniformity [25]. Considering these characteristics, sound waves can penetrate the tumor to form a posterior echo enhancement without excessive reflection or attenuation. However, previous studies [23, 24, 26-28] have suggested that $\mathrm{PR}+$ breast cancers were more frequently associated with low degrees of malignancy and low histological grades, and $\mathrm{Xu}$ et al. indicated directly that the internal necrosis was related to PR negativity. In the training set, $67.6 \%(507 / 739)$ of PR+ lesions were histological grade I/II. Therefore, it's reasonable that posterior enhancement was negatively correlated with $\mathrm{PR}+$, and that our findings indicated that tumors with posterior enhancement were about 0.4 times more likely to express $\mathrm{PR}+$ than tumors with no change in posterior echogenicity.

HER2 receptors are located in the cell membrane which are involved in the transmission of signals that control normal cell growth and differentiation [29, 30]. HER2 overexpression plays a vital role in tumor transformation and tumorigenesis [29]. In Group III, palpable ALN, shape (round, irregular), and calcifications were independent predictors of HER2+. In previous studies, the presence of calcifications on US or mammography were related to HER2 + [23,31], which mainly manifests as pleomorphic and branching calcifications on mammography [31]. Several studies $[15,23]$ suggested that tumor shape was not related to HER2 status; in contrast, our findings suggested that round and irregular shapes were more than two and seven times more likely to appear HER2 positive than oval tumors, respectively. This may only be the relevant in studies that explore the related features of HER2 status in controlled groups. The HER2+ subtype are prone to ALN metastasis (approximately 60\% [32]), so it is understandable that our study found that palpable ALN were significantly associated with HER2+.

The HER2+ subtype has a high degree of malignancy and the main pathological type is invasive ductal carcinoma. This study attempted to predict the HER $2+$ subtype on the basis of the independent predictors of three biomarkers (i.e. age, palpable ALN, posterior acoustic features, calcifications, and shape). Some studies have also shown that the HER2+ subtype was associated with posterior acoustic features, calcifications and 
age $[2,16,17]$. The diagnostic efficacy of the model in this study was AUC 0.697 in the training set and AUC 0.725 in the test set. To our best knowledge, regarding aspects on predicting breast cancer subtypes based on conventional US feature models, only the study by Zhang et al. [2] was found to have $87.9 \%$ accuracy in predicting the HER2+ subtypes using an ensemble decision method based on clinical and US features. Although the present model had inferior performance, however, the two models defined HER2+ subtypes differently, with the former having a $10 \%$ cutoff for ER and PR positivity compared with the currently widely used cutoff of $1 \%$. Therefore, the results of this study may be more in line with the current clinical situation. Besides, the diagnostic efficiency of our model was moderate, suggesting the feasibility of predicting breast cancer subtypes based on the related features of biomarkers and providing an alternative modeling idea for predicting subtypes.

This study has certain limitations. First, it was a retrospective study and the US diagnosis was subjective. However, all enrolled cases met uniform imaging standards and had multiple US images to ensure maximum integrity of US features of breast lesions. Additionally, two radiologists independently reviewed the US images, which reduced the subjectivity to a certain extent. Second, despite the considerable size of the data, they were obtained only from a single center. Therefore, data of breast cancer patients from other centers are needed to increase data objectivity. Third, no new image analysis methods were performed, including radiomics or deep learning. The US images in this study were derived from funded projects and have unified image acquisition standards. Thus, they are suitable for image analysis using radiomics to study the relationship between radiomics features and breast cancer subtypes or biomarkers in breast cancer. Although some research in this area [33, 34] has been conducted, some areas could be still improved. However, it is worth noting that data is often affected by uncertainty or inaccuracy. Therefore, it would be necessary to use a fuzzy prediction technique proposed by $\mathrm{M}$ Cacciola et al. [35]. We will include this as part of our research in the future.

\section{Conclusions}

Our research suggested that PR status was related to posterior acoustic features, and HER2 status to shape and calcifications. These findings may help non-invasively predict the HER2+ subtype and the status of the biomarkers, and provide an alternative modeling idea for predicting subtypes. Perhaps future studies on the correlation between the expression status of ER, PR, and
HER2 and imaging features could consider the influence of biomarkers on each other and might try to change the approach of exploration. In summary, the results could help in formulating an initial impression and treatment plan prior to surgery.

\begin{abstract}
Abbreviations
ER: Estrogen receptor; PR: Progesterone receptor; HER-2: Human epidermal growth factor receptor-2; US: Ultrasound; IHC: Immunohistochemistry; FISH: Fluorescent in-situ hybridization; CISH: Chromogenic in-situ hybridization; ALN: Axillary lymph node; BMI: Body mass index; AUC: Area under the receiver operating characteristic curve; ACC: Accuracy; SENS: Sensitivity; SPEC: Specificity; Negative: -; Positive: + .
\end{abstract}

\section{Acknowledgements \\ We would like to thank ze-zhou wang, chang-ming zhou for statistics consulting.}

\section{Authors' contributions}

Conception and design: JZ, AJ, SZ, CC; Administrative support: SZ, CC; The acquisition of data: JL, WZ, YH, QZ, LQ, JW; Collection and assembly of data: JL, WZ, YH, QZ, LQ; Data analysis and interpretation: JZ, AJ; writing the manuscript: All authors; All authors read and approved the final manuscript.

\section{Funding}

This work is supported by the National Natural Science Foundation of China (81830058, 81801701), the Science and Technology Commission of Shanghai Municipality (18411967400), Shanghai Engineering Research Center of Artificial Intelligence Technology for Tumor Diseases (19DZ2251800) and Xuhui

District Artificial Intelligence Medical Hospital Cooperation Project (2020-008).

\section{Availability of data and materials}

The datasets used and/or analysed during the current study are available from the corresponding author on reasonable request.

\section{Declarations}

\section{Ethics approval and consent to participate}

The study was conducted in accordance with the Declaration of Helsinki (as revised in 2013). The study was approved by the Ethics Committee of Fudan University Shanghai Cancer Center (No. 2107238-18) and individual consent for this retrospective analysis was waived.

Consent for publication

Not applicable.

\section{Competing interests}

The authors declare that they have no competing interests.

\section{Author details}

${ }^{1}$ Department of Ultrasound, First Floor, Building 3, Fudan University Shanghai Cancer Center, No. 270 Dong'an Road, Xuhui District, Shanghai, China.

${ }^{2}$ Department of Breast Surgery, Fudan University Shanghai Cancer Center, Shanghai, China. ${ }^{3}$ Department of Oncology, Shanghai Medical College, Fudan University, Shanghai, China.

Received: 21 October 2021 Accepted: 23 November 2021

Published online: 02 December 2021

\section{References}

1. Siegel RL, Miller KD, Jemal A. Cancer statistics, 2020. CA Cancer J Clin. 2020;70(1):7-30.

2. Zhang L, Li J, Xiao Y, Cui H, Du G, Wang Y, et al. Identifying ultrasound and clinical features of breast cancer molecular subtypes by ensemble decision. Sci Rep. 2015;5:11085. 
3. Goldhirsch A, Winer EP, Coates AS, Gelber RD, Piccart-Gebhart M, Thürlimann $B$, et al. Personalizing the treatment of women with early breast cancer: highlights of the St Gallen International Expert Consensus on the Primary Therapy of Early Breast Cancer 2013. Ann Oncol. 2013;24(9):2206-23.

4. Bardou VJ, Arpino G, Elledge RM, Osborne CK, Clark GM. Progesterone receptor status significantly improves outcome prediction over estrogen receptor status alone for adjuvant endocrine therapy in two large breast cancer databases. J Clin Oncol. 2003;21(10):1973-9.

5. Slamon DJ, Clark GM, Wong SG, Levin WJ, Ullrich A, McGuire WL. Human breast cancer: correlation of relapse and survival with amplification of the HER-2/neu oncogene. Science. 1987;235(4785):177-82.

6. Wolff AC, Hammond ME, Hicks DG, Dowsett M, McShane LM, Allison KH, et al. Recommendations for human epidermal growth factor receptor 2 testing in breast cancer: American Society of Clinical Oncology/College of American Pathologists clinical practice guideline update. J Clin Oncol. 2013;31(31):3997-4013.

7. Wolff AC, Hammond MEH, Allison KH, Harvey BE, Mangu PB, Bartlett JMS, et al. Human epidermal growth factor receptor 2 testing in breast cancer: American Society of Clinical Oncology/College of American Pathologists clinical practice guideline focused update. J Clin Oncol. 2018;36(20):2105-22.

8. Raji A. Human epidermal growth factor receptor 2 testing recommendation. J Clin Oncol. 2007;25(25):4020-1 (author reply 1-3).

9. El-Bastawissi AY, White E, Mandelson MT, Taplin S. Variation in mammographic breast density by race. Ann Epidemiol. 2001;11(4):257-63.

10. Burkett BJ, Hanemann CW. A review of supplemental screening ultrasound for breast cancer: certain populations of women with dense breast tissue may benefit. Acad Radiol. 2016;23(12):1604-9.

11. Najjar H, Easson A. Age at diagnosis of breast cancer in Arab nations. Int J Surg. 2010;8(6):448-52.

12. Leong SP, Shen ZZ, Liu TJ, Agarwal G, Tajima T, Paik NS, et al. Is breast cancer the same disease in Asian and Western countries? World J Surg. 2010;34(10):2308-24.

13. Zhang L, Liu YJ, Jiang SQ, Cui H, Li ZY, Tian JW. Ultrasound utility for predicting biological behavior of invasive ductal breast cancers. Asian Pac J Cancer Prev. 2014;15(19):8057-62.

14. Liu Y, Xiong W, Xu JM, Liu YX, Zhang J. Correlations between the expression of C-erB-2, CD34 and ER in breast cancer patients and the signs of conventional ultrasonography and ultrasound elastography. Eur Rev Med Pharmacol Sci. 2018;22(17):5539-45.

15. $\mathrm{Xu} \mathrm{J,} \mathrm{Li} \mathrm{F,} \mathrm{Chang} \mathrm{F.} \mathrm{Correlation} \mathrm{of} \mathrm{the} \mathrm{ultrasound} \mathrm{imaging} \mathrm{of} \mathrm{breast} \mathrm{cancer}$ and the expression of molecular biological indexes. Pak J Pharm Sci. 2017;30(4 (Suppl.)):1425-30.

16. WuT, Li J, Wang D, Leng X, Zhang L, Li Z, et al. Identification of a correlation between the sonographic appearance and molecular subtype of invasive breast cancer: a review of 311 cases. Clin Imaging. 2019;53:179-85.

17. Rashmi S, Kamala S, Murthy SS, Kotha S, Rao YS, Chaudhary KV. Predicting the molecular subtype of breast cancer based on mammography and ultrasound findings. Indian J Radiol Imaging. 2018;28(3):354-61.

18. Wang D, Zhu K, Tian J, Li Z, Du G, Guo Q, et al. Clinicopathological and ultrasonic features of triple-negative breast cancers: a comparison with hormone receptor-positive/human epidermal growth factor receptor2-negative breast cancers. Ultrasound Med Biol. 2018;44(5):1124-32.

19. Sturesdotter L, Sandsveden M, Johnson K, Larsson AM, Zackrisson S, Sartor H. Mammographic tumour appearance is related to clinicopathological factors and surrogate molecular breast cancer subtype. Sci Rep. 2020;10(1):20814.

20. Mendelson EB, Böhm-Vélez M, Berg WA. ACR BI-RADS ${ }^{\circledR}$ ultrasound. ACR BI-RADS ${ }^{\circledR}$ Atlas, breast imaging reporting and data system. Reston: American College of Radiology; 2013.

21. American College of Radiology(ACR). ACR BI-RADS-ultrasound. ACR breast imaging reporting of data system, Breast Imaging Atlas. Reston: American College of Radiology; 2003.

22. Adler DD, Carson PL, Rubin JM, Quinn-Reid D. Doppler ultrasound color flow imaging in the study of breast cancer: preliminary findings. Ultrasound Med Biol. 1990;16(6):553-9.

23. Kim SH, Seo BK, Lee J, Kim SJ, Cho KR, Lee KY, et al. Correlation of ultrasound findings with histology, tumor grade, and biological markers in breast cancer. Acta Oncol. 2008;47(8):1531-8.
24. Zhu X, Ying J, Wang F, Wang J, Yang H. Estrogen receptor, progesterone receptor, and human epidermal growth factor receptor 2 status in invasive breast cancer: a 3,198 cases study at National Cancer Center. China Breast Cancer Res Treat. 2014;147(3):551-5.

25. Stavros AT, Thickman D, Rapp CL, Dennis MA, Parker SH, Sisney GA. Solid breast nodules-use of sonography to distinguish benign and malignant lesions. Radiology. 1995;196(1):123-34.

26. Irshad A, Leddy R, Pisano E, Baker N, Lewis M, Ackerman S, et al. Assessing the role of ultrasound in predicting the biological behavior of breast cancer. AJR Am J Roentgenol. 2013;200(2):284-90.

27. Rakha EA, El-Sayed ME, Lee AH, Elston CW, Grainge MJ, Hodi Z, et al. Prognostic significance of Nottingham histologic grade in invasive breast carcinoma. J Clin Oncol. 2008;26(19):3153-8.

28. Au FWF, Ghai S, Lu Fl, Moshonov H, Crystal P. Histological grade and immunohistochemical biomarkers of breast cancer: correlation to ultrasound features. J Ultrasound Med. 2017;36(9):1883-94.

29. Neve RM, Lane HA, Hynes NE. The role of overexpressed HER2 in transformation. Ann Oncol. 2001;12(Suppl 1):S9-13.

30. Rubin I, Yarden Y. The basic biology of HER2. Ann Oncol. 2001;12(Suppl 1):S3-8.

31. Radenkovic S, Konjevic G, Isakovic A, Stevanovic P, Gopcevic K, Jurisic V. HER2-positive breast cancer patients: correlation between mammographic and pathological findings. Radiat Prot Dosimetry. 2014;162(1-2):125-8.

32. Kennecke H, Yerushalmi R, Woods R, Cheang MC, Voduc D, Speers $\mathrm{CH}$, et al. Metastatic behavior of breast cancer subtypes. J Clin Oncol. 2010;28(20):3271-7.

33. Jiang M, Zhang D, Tang SC, Luo XM, Chuan ZR, Lv WZ, et al. Deep learning with convolutional neural network in the assessment of breast cancer molecular subtypes based on US images: a multicenter retrospective study. Eur Radiol. 2021;31(6):3673-82.

34. Mohaiminul Islam M, Huang S, Ajwad R, Chi C, Wang Y, Hu P. An integrative deep learning framework for classifying molecular subtypes of breast cancer. Comput Struct Biotechnol J. 2020;18:2185-99.

35. Cacciola M, Pellicano D, Megali G, Lay-Ekuakille A.Versaci M, Morabito FC. Aspects about air. Pollution prediction on urban environment. In: 4th IMEKO TC19 Symposium on Environmental Instrumentation and Measurements 2013: Protection Environment, Climate Changes and Pollution Control Pages 15-202013 4th IMEKO TC19 Symposium on Environmental Instrumentation and Measurements 2013: Protection Environment, Climate Changes and Pollution Control, 3 June 2013 through 4 June 2013, Code 102275

\section{Publisher's Note}

Springer Nature remains neutral with regard to jurisdictional claims in published maps and institutional affiliations.

Ready to submit your research? Choose BMC and benefit from:

- fast, convenient online submission

- thorough peer review by experienced researchers in your field

- rapid publication on acceptance

- support for research data, including large and complex data types

- gold Open Access which fosters wider collaboration and increased citations

- maximum visibility for your research: over $100 \mathrm{M}$ website views per year

At BMC, research is always in progress.

Learn more biomedcentral.com/submissions 